\title{
Occupational asthma due to tylosin tartrate
}

\author{
H S LEE, ${ }^{1}$ Y T WANG, ${ }^{2}$ C T YEO, ${ }^{2}$ K T TAN, ${ }^{1}$ K V RATNAM ${ }^{3}$ \\ From the Department of Industrial Health, ${ }^{\prime}$ Ministry of Labour, Medical Unit III, Tan Tock Seng Hospital, ${ }^{2}$ \\ and Middle Road Hospital, ${ }^{3}$ Singapore
}

Tylosin is a macrolide antiobiotic produced by fermentation from a culture of streptomyces fradiae. Both tylosin $\left(\mathrm{C}_{47} \mathrm{H}_{77} \mathrm{NO}_{17}, \mathrm{MW}: 904 \cdot 2\right)$ and tylosin tartrate $\left(\mathrm{C}_{47} \mathrm{H}_{77} \mathrm{NO}_{17} . \mathrm{C}_{4} \mathrm{H}_{6} \mathrm{O}_{6}, \mathrm{MW}: 1054 \cdot 3\right)$ have found wide practical use as an animal health and growth agent. They are used principally to combat dysentery in pigs and respiratory infections in poultry and may be added to the animal feed, to the drinking water, or given by injection. Because of their low toxicity they have been permitted for use as a food additive for both animals and man. Occupational contact dermatitis to tylosin has been reported among animal feed handlers, farmers, veterinary surgeons, and factory workers. ${ }^{1-5}$ Positive patch tests to both tylosin and tylosin tartrate have been reported in some of these cases. ${ }^{2-5}$ We report the first case of asthma induced by occupational exposure to tylosin tartrate.

\section{Case report}

A 25 year old woman worked for two years in a small factory producing pharmaceutical products for veterinary use. As a laboratory technician, she was exposed to various chemicals during the weighing and mixing process. She noticed that whenever she was exposed to tylosin tartrate powder she would develop a blocked nose, headache, and breathlessness about one to two hours later. There was associated cough with sputum. She would feel tired and feverish at night after returning home from work. The breathlessness was often worse in the late evening. The factory prepared tylosin tartrate solution for injection only once every month during two days. She was free of symptoms on the other days of the month when tylosin tartrate was not used. She started having these symptoms about one month after joining the factory.

She had a history of vasomotor rhinitis even before joining the factory. There was no history of asthma or eczema.

\section{OCCUPATIONAL EXPOSURE}

The preparation of tylosin tartrate solution was observed and the dust exposure level monitored during the mixing process. The mixing was carried out $\overrightarrow{\vec{H}}$ in a tank containing 201 of distilled water. The worker $\omega$ added small quantities of citric acid, sodium citrate,, $\mathbb{\Phi}^{\circ}$ and sodium formaldehyde sulphoxal. Twenty kilograms of pure tylosin tartrate powder was then $\hat{\sigma}^{-}$ added in several portions. This was done by scooping $v$ the powder from a bag and pouring it into the tank. $\vec{c}$ The process was visibly dusty and took about 2300 minutes. The mixture was blended by a small rotating propeller. No dust extractor was used. After that aglycol and an alcohol were added.

A quartz crystal microbalance cascade impactor was used to monitor the dust concentrations at the $\overrightarrow{0}$ breathing zone of the worker. The average concentra- $-\infty$ tions of exposure to respirable $(<10 \mu \mathrm{m})$ and nonrespirable dust during the mixing of tylosin tartrate were $0.50 \mathrm{mg} / \mathrm{m}^{3}$ and $0.37 \mathrm{mg} / \mathrm{m}^{3}$ respectively. The aerodynamic diameter of the respirable dust was. predominantly found to be in the 4-9 $\mu \mathrm{m}$ range. The background total dust concentration was $0.08 \mathrm{mg} / \mathrm{m}^{3} . \stackrel{\varrho}{\vec{\pi}}$ There is no threshold limit for comparison.

Two workers were engaged in this process. The other worker had no symptoms. The supervisor of the section, however, had symptoms of rhinitis and chest tightness related to exposure to tylosin tartrate. $\mathrm{He}_{\mathbb{\Phi}}^{\odot}$ would avoid exposure to the chemical and refused any? medical investigations.

When not preparing tylosin tartrate solution the workers handled various other chemicals including sulphonamide, streptomycin sulphate, chloramphenicol, oxytetracycline, penicillin, and local anaesthetics. 음

\section{BRONCHIAL PROVOCATION TESTING}

Bronchial provocation testing was carried out as an N inpatient. The patient used a small spoon to transfer about $5 \mathrm{~kg}$ of pure tylosin tartrate powder (from the factory) between the two compartments of a tray. This $\tilde{N}$ was done in a small room for about 10 minutes.

Two hours later she started complaining of ao blocked nose and her FEV ${ }_{1}$ had fallen to $83 \%$ of the pre-challenge value. The ratio of the $\mathrm{FEV}_{1}$ to the $\stackrel{+}{+}$ forced vital capacity $\left(\mathrm{FEV}_{1} \mathrm{FVC} \%\right.$ ) was $94 \%$. Five 7 hours after exposure her FEV , had fallen by more than half to $1 \cdot 21$. $\mathrm{FEV}_{1} / \mathrm{FVC} \%$ was $59 \%$. Half an hour later rhonchi were detected in her lungs and she had $a \stackrel{\mathbb{Q}}{\varrho}$ 
Occupational asthma due to tylosin tartrate

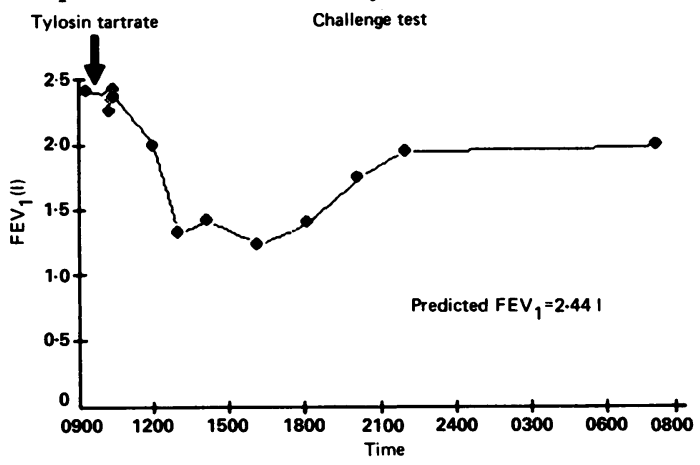

$F E V_{1}$ after exposure to tylosin tartrate.

mild non-productive cough. Thereafter the $\mathrm{FEV}_{1}$ readings improved (figure). No fever was observed. Serial measurements of the carbon monoxide transfer factor did not show any significant reduction.

\section{OTHER INVESTIGATIONS}

The patient's blood eosinophil count was $5 \%$ of a total white cell count of 6800 . Her total $1 \mathrm{gE}$ concentration was $500 \mathrm{IU} / \mathrm{ml}$ (normal range: $5-400 \mathrm{IU} / \mathrm{mg}$ ). Chest $x$ ray examination results were normal. She had nonspecific bronchial hyperractivity as assessed by histamine inhalation challenge, the $\mathrm{PD}_{20} \mathrm{FEV}_{1}$ being $0.054 \mathrm{mg}$. Prick test and patch test to tylosin tartrate was not carried out.

\section{Discussion}

Our patient had occupational asthma and rhinitis from exposure to tylosin tartrate. Occupational asthma may coexist with occupational rhinitis. ${ }^{6}$ Her supervisor had similar symptoms. Our patient was also exposed to other potentially sensitising chemicals but she gave a clear history that her symptoms were only associated with the use of tylosin tartrate. The bronchial provocation test confirmed this.

It is interesting that whereas there have been numerous reports of contact dermatitis, ${ }^{1-5}$ there have been none of asthma from tylosin or tylosin tartrate. It has been suggested that the circumstances of exposure largely determine whether asthma or dermatitis results. ${ }^{7}$ Without details on the dust concentrations and particle sizes it is difficult to compare the circumstances of exposure in detail. It would be expected, however, that in most cases both skin contact and airborne exposure would occur. Verbov described five cases of tylosin dermatitis from a factory. ${ }^{5}$ He noted that one of his cases had also complained of dyspnoea for about six months. The case had been in contact with both tylosin and cephalexin for six to seven months and had facial, neck, and chest erythema and excoriated eczema over popliteal fossae. The distribution of the rash could suggest some airborne exposure to tylosin. The possibility that the worker could have occupational asthma from tylosin was not excluded.

Cases of occupational asthma from tylosin or tylosin tartrate have probably not been previously recognised. Animal feed handlers, veterinary surgeons, farmers, and factory workers handling tylosin or tylosin tartrate are potentially at risk of developing occupational asthma. Steps should be taken to reduce all occupational exposure to inhalable tylosin and tylosin tartrate.

\section{References}

1 Fisher AA. Allergic contact dermatitis in animal feed handlers. Cutis 1975;16:201-2.

2 Neldner KH. Contact dermatitis from animal feed additives. Arch Dermatol 1972;106:722-3.

3 Veien NK, Hattel T, Justesen O, Norholm A. Occupational contact dermatitis due to spiramycin and/or tylosin among farmers. Contact Dermatitis 1980;6:410-3.

4 Hjorth N, Weismann K. Occupational dermatitis among veterinary surgeons caused by spiramycin, tylosin and penethamate. Acta Derm Venereol 1973;53:229-32.

5 Verbov J. Tylosin dermatitis. Contact Dermatitis 1983;9:325-6.

6 Salvaggio JE, Taylor G, Weill H. Occupational asthma and rhinitis. In: Merchant JA ed. Occupational respiratory diseases. Washington: US Department of Health and Human Services, 1986:461-75.

7 Burge PS. Occupational asthma and dermatitis: points of contact. Clin Exp Dermatol 1981;6:235-41. 